\title{
La espiritualidad cristiana en el hablante de Domingo Gómez Rojas*
}

\author{
Carolina González Varas**
}

\section{Resumen}

La figura y obra poética de Domingo Gómez Rojas se ha dado a conocer, principalmente, por ser la obra de un estudiante encarcelado por "subversivo" y asesinado injustamente. En esta investigación nos alejamos de aquella perspectiva que hasta hace pocos años acaparó la atención de la crítica y revisamos un aspecto desatendido por sus estudiosos: la espiritualidad cristiana de su poética. Específicamente, se examina la cosmovisión cristiana del hablante lírico en el contexto del proceso de secularización, propio de la modernidad. Posteriormente, se confronta la espiritualidad del hablante con la del autor, con el propósito de ampliar el conocimiento de su poesía y de descubrir qué es lo característico y novedoso que realmente distingue la obra del poeta en este ámbito.

Palabras clave: Poesía, cosmovisión, espiritualidad cristiana, Domingo Gómez Rojas.

\section{The christian spirituality on the speaker of Domingo Gómez Rojas}

\begin{abstract}
Domingo Gómez Rojas's poetry and figure has been known, mainly, because of being the work of an unjustly imprisoned and killed student. This research attempts to move beyond this perspective that, until recent years, captured the attention of critics, and is entering into a clearly unattendent topic: his poetry's christian spirituality. Specifically, we are going to examine the lyric speaker's christian worldview in the secularization context of modernity. We will confront the vision of the speaker with the one of the author, with the purpose of expanding the knowledge of his poetry and discover the characteristics that really distinguish this poet's work.
\end{abstract}

Keywords: Poetry, worldview, christian spirituality, Domingo Gómez Rojas.

* Artículo presentado en el congreso "Chile mira a sus poetas" el día 28 de octubre de 2009. Cabe señalar que se han hecho rectificaciones desde entonces.

** Alumna del Magíster en Letras mención Literatura de la Pontificia Universidad Católica de Chile. Este artículo es parte de los resultados del proyecto Fondecyt No 1090735 "Las vanguardias literarias: revistas, poesía e intelectuales 1920-1930" (2009- 2011). Investigador responsable Dr. Patricio Lizama A. y co-investigadora Dra. Paula Miranda H. La autora es tesista en este proyecto.carigonzalezv@gmail.com 


\section{Introducción}

El presente artículo se propone indagar en la cosmovisión religiosa del hablante lírico de Gómez Rojas. A través de una selección de sus poemas, se identificarán y examinarán las características de la relación entre el hablante y la divinidad en el contexto del proceso de secularización propio de la modernidad. Luego, se comparará la cosmovisión cristiana del hablante con la del poeta.

Sabemos que Gómez Rojas era un hombre conocedor y respetuoso del cristianismo. En efecto, sus poemas de inspiración cristiana demuestran que el autor tenía una acabada preparación en los textos de las Sagradas Escrituras, su historia e iconografía. Sin embargo, dichos poemas no sólo están marcados por una actitud piadosa sino que, a la vez, traslucen la frustración del hablante ante el incumplimiento, por parte de los hombres, del mensaje de amor y solidaridad que Dios envió al mundo a través de Jesucristo.

La hipótesis a desarrollar sugiere que, desencantado con la indolencia del mundo que lo rodeaba, Gómez Rojas deserta de la mediación de una iglesia institucionalizada como instancia única para encauzar su fe, y desarrolla un culto cristiano íntimo. Esto se refleja concretamente cuando su voz poética instaura nuevos significados y valores para el imaginario cristiano conocido. Por ejemplo, el hablante analoga el rol social de la religión con el de la poesía y la misión del poeta en la sociedad con la misión de Jesucristo en la humanidad, respectivamente. Asimismo, identifica el lugar de lo trascendente ya no con un reino celestial metafísico, como habitualmente se hace, sino con el espacio astral concreto. Por último, el hablante observa el evento de la muerte como una posibilidad de terminar con los padecimientos que le impone la vida, pero no como un umbral hacia la redención eterna, como se enseña en el catecismo de la Iglesia Católica. Estos tres rasgos del hablante describen un giro materialista, en términos filosóficos, en la relación entre el hablante y lo divino, dando cuenta del proceso de secularización en el cual se inserta esta lírica.

Para precisar los rasgos de la espiritualidad del hablante, proponemos analizar las unidades de sentido presentes en los diversos textos seleccionados y contrastarlas con declaraciones del propio autor, de sus compañeros y de sus biógrafos. El corpus estudiado está constituido por cuatro poemas: "Yoísmo", "Autorretrato", "Voy por el Mundo" y "Profanación". Todos ellos pertenecientes al Poemario Elegías, publicado por primera vez en Santiago en el año 1935 por la editorial Nascimento. 
Lamentablemente, se desconocen las fechas de elaboración de cada una de las piezas, pero se especula que la mayor parte de ellas fue escrita entre los años 1912 y 1917, periodo de mayor producción del autor.

\section{La inexplorada poética cristiana de Gómez Rojas}

Las nefastas circunstancias del encarcelamiento y muerte de este poeta han concentrado gran parte de la atención que la academia ha dedicado a este autor, a veces, en desmedro de un interés crítico más amplio sobre su obra. En el momento en que Gómez Rojas muere (29 de septiembre de 1920), diversas revistas de la época publicaron una serie de panegíricos destacando la vehemencia con que el poeta defendió sus creencias y el talento con que llevó a cabo su vocación. El carácter apologético de estas revistas lo calificó como un poeta prometedor cuya oportunidad de desarrollar su arte le habría sido arrebatada demasiado pronto.

Por ejemplo, Manuel Rojas, amigo del poeta, señala que "[...] José Domingo Gómez Rojas no alcanzó, sin embargo, a madurar plenamente; pero si se consideran las virtudes y las condiciones que poseía, se ve, con dolor, que pudo haber llegado a ser un excelente hombre y un buen escritor." (Rojas 28) Lo mismo ocurre con el siguiente fragmento del discurso fúnebre que recita el amigo y compañero de labores Luis A. Baeza en representación del diario Última Hora: "Hoy, señores, lamentamos la pérdida de un talento reconocido y elogiado por los más altos intelectuales de América y España, de un pensador que tuvo la valentía de emitir y propagar las puras ideas de renovación que envuelven al mundo con su luz infinita." (Moraga 256) Desafortunadamente, este tipo de arengas dice realmente poco sobre su trabajo, pues se concentran, sobre todo, en su carácter de héroe estudiantil.

Transcurridos más de noventa años desde la muerte del poeta, resulta curioso que aún tan pocos investigadores y antologadores se hayan detenido a examinar en detalle su creación poética más allá de las trágicas circunstancias de su muerte. En este sentido, compartimos la opinión del profesor Iván Droguett quien, en su breve artículo "Gómez Rojas, un poeta crepuscular" pondera la obra del poeta y señala: "La poesía de Gómez Rojas es de segundo orden, carece de un estilo en cuanto a «forma verbal templada por el estado de ánimo»; escribe a una edad temprana y muere demasiado joven; su impulso juvenil da mayor importancia al contenido objetivo que a la verdad interior, cae en la poesía edificante demasiado obvia." (Droguett 136) 
Desde que Fabio Moraga y Carlos Vega repararon en la falta de atención que ha tenido la poesía de inspiración cristiana de Gómez Rojas, hemos sentido la necesidad de indagar sobre este tema. Dejaremos a un lado los alcances casi legendarios sobre el deceso del poeta y nos dedicaremos a explorar su poesía con el fin de ponderar su trabajo bajo una perspectiva crítica y ver qué elementos conforman su originalidad.

\section{El desencanto de Gómez Rojas y su consuelo en la poesía}

Durante las dos primeras décadas del siglo XX, nuestro autor, fiel a su férreo compromiso social, considera que parte de la jerarquía de la Iglesia Católica y algunos de sus fieles más influyentes a nivel nacional han hecho poco en favor de los estratos sociales más desfavorecidos y, en lugar de eso, se han dedicado a disfrutar de magnos festines. Para él, esa feligresía aristocratizante y monopolizadora del poder político y económico se afanó en profitar de sus relaciones con la Iglesia Católica haciéndola desatender el mandato cristiano de la caridad. Subrayemos, entonces, que la crítica de Gómez Rojas no está dirigida hacia la religión como sistema de creencias sino a la inconsecuencia de ciertos dirigentes políticos y parte de la esfera de poder católica.

Ciertamente, el desencanto del poeta no sólo surgió al corroborar que esta Iglesia no protegía al pueblo. Su decepción se funda en múltiples causas. La gran pobreza en que creció, contrastada con la desidia de la clase política para ofrecer solución a este problema tan extendido en Chile, infundió en él un creciente sentimiento de impotencia que con el transcurrir del tiempo fue alimentando en él un gran deseo de protestar. Sin embargo, poco podía hacer desde esta situación ya que sus posibilidades reales de ser oído eran prácticamente nulas de no aunar esfuerzos con quienes compartiesen sus necesidades materiales e inquietudes intelectuales. Iván Droguett expresa aquella urgencia de Gómez Rojas en los siguientes términos: "[Gómez Rojas] [v]ive la angustiosa dualidad social de la época: la abulia de una clase dirigente egoísta y la potencialidad casi ilimitada de un pueblo impedido" (136). Es a través de la poesía que Gómez Rojas desarrollará su potencialidad.

Además de descargar su rabia contra las injusticias sociales mediante la poesía, Gómez Rojas encontró otra forma de hacerse oír y también 
de consolarse. Su participación en la Iglesia Metodista parece haberle renovado la esperanza en las acciones sociales practicadas institucional y sistemáticamente. La doctrina del metodismo llama a buscar la salvación personal a través de una misión cristiana colectiva de servicio al mundo, la búsqueda permanente de la justicia, la realización de trabajos caritativos y, sobre todo, el alivio del hermano sufriente y carenciado. Pareciese, entonces, que nuestro autor encuentra más en el metodismo que en el catolicismo la realización de valores tan preciados para él como la fraternidad y la solidaridad.

Bajo este contexto Gómez Rojas se alza como un símbolo para los jóvenes, a quienes alienta a comprometerse para luchar contra las injusticias sociales. En una de sus arengas se opone fervorosamente a la difusión de folletos y revistas católicas, que eran incondicionales al gobierno, e intenta animar a sus compañeros metodistas para que mantengan una prensa igualmente activa e influyente, señalando: "Los romanistas cuentan con treinta y ocho poderosos brazos, que empujan la propaganda clerical [...] Son sus treinta y ocho diarios [...] Chile sufre, según mi juicio, la plaga que llamaría «Prensa Clerical»." (Moraga 68) Este mismo rechazo a las injusticias e instrumentalizaciones políticas también se hace patente en el poemario Rebeldías Líricas (1913) que, según Andrés Sabella: "[... expresó su protesta, valiente y caliente por la explotación del hombre por el hombre [...]" (14).

El deseo de Gómez Rojas de "destruir los restos decimonónicos", según señala Iván Droguett, unido a su rechazo casi militante hacia las cúpulas de poder político y a las de la Iglesia Católica, no lo dejan satisfecho. Es más, estas circunstancias lo inducen a fugarse drásticamente del sistema tanto por desilusión como por desesperación. Poco a poco, este lírico se documenta y comienza a abrazar los preceptos del anarquismo. Pero, este vuelco tampoco le brindó satisfacción.

Ante la incapacidad real de subvertir este sistema, la única fuga realizable sería hacia la poesía. Es por ello que se vierte con esmero en esta tarea, casi enajenándose de la realidad y asumiendo una postura radical de desprecio al mundo. Así, la inspiración cristiana de Gómez Rojas brota en su creación poética desde la inquietud genuina de un sujeto marginado que, aun cuando se ha apartado del culto oficial por disentir con sus cúpulas de poder, conserva su fe en Cristo. Con todo, surge en él el deseo de expresar su fe de una forma particular. 


\section{Rasgos de espiritualidad cristiana en el hablante lírico de Gómez Rojas}

Basta tan sólo una lectura a los dos últimos poemarios de Gómez Rojas para advertir que su hablante tiene una marcada tendencia cristiana. Aun cuando no contamos con suficientes antecedentes para afirmar que durante su niñez el autor recibió instrucción formal en alguna religión en particular, intuimos -a juzgar por su devoción a la virgen María-, que puede haber sido aleccionado en la doctrina católica. Lo que sí se puede afirmar con certeza es que estos poemas no son de naturaleza confesional pues no se ofrecen como una proclama de fe hacia principios teologales incuestionables, ni siquiera como afirmación de ellos.

En estos poemas, el contacto del hablante con lo divino es íntimo $y$, por tanto, original. Decimos "íntimo" porque la voz poética se vierte hacia su interioridad para examinar su conciencia cristiana y, desde allí, se dirige hacia lo divino. Por otro lado, decimos que este contacto es "original" porque emerge de una experiencia personal de lo divino, es decir, desde una forma única de percibirlo. Se podría afirmar que, cuando Gómez Rojas se fuga del mundo, se ampara en su hablante, ya sea para buscar refugio y dar sentido a sus experiencias de sufrimiento o, simplemente, para cultivar su vínculo con la divinidad cristiana.

A continuación describimos los motivos cristianos identificados en los poemas seleccionados y los analizaremos con más detalle durante los siguientes acápites. El primero de ellos destaca la aparición frecuente de figuras cristianas como Dios, la virgen María y el Hijo de Dios. Centraremos el análisis en la figura de Jesucristo subrayando como motivo la analogía que establece el hablante entre la misión de Jesucristo en el mundo y el rol del poeta en la sociedad. La segunda característica de esta cosmovisión es la distinción y enfrentamiento entre la esfera de lo mundano y la de lo sagrado. Entre estos dos polos se marca una férrea línea divisoria que ubica al hablante entre lo rechazable del mundo y el deseo de escapar de él a través de la muerte. La tensión suele resolverse en una actitud de impotencia ante el devenir mundano, lo que acrecienta el deseo de muerte del hablante. El tercer rasgo de esta cosmovisión cristiana es la concepción de la vida como tránsito hacia un estado de paz que se espera esté después de la muerte. 


\subsection{Correspondencias entre la misión de Cristo en la humanidad y el rol del poeta en la sociedad}

La intertextualidad bíblica es una característica persistente en la obra de este poeta. No sólo por estilizar pasajes del Génesis o de algunos de los Evangelios, sino por las recurrentes alusiones a personajes e instancias icónicas del cristianismo. Desde la imagen veterotestamentaria de "Yahvé" hasta la "Virgen María" e incluso la imagen del "ángel caído" están presentes en su obra. Existen también reiteradas alusiones a la Iglesia -entendida tanto como "espacio sacralizado" y como "congregación de fieles"-. Ante esta institución el hablante despliega una actitud templada, esto es, de distancia respetuosa. Otro ejemplo de ello es la referencia al sacramento cristiano de la Eucaristía -compartido por católicos y metodistas-. Este símbolo de la gracia divina es presentado en el poema "Profanación" como un instante ante el cual se debe guardar el mayor de los respetos pues se reconoce que la materia se colma de un nuevo significado después de la Consagración.

Con todo, la imagen cristiana más trabajada por el hablante es la de Jesucristo, sacrificado por ser el anunciador de nuevas verdades, por ser Aquél que se revela a Sí mismo en su palabra, el Verbo Divino. Si al Hijo de Dios le correspondió anunciar las Verdades Eternas, al poeta le corresponde anunciar las verdades hodiernas, exhortando la precaria conciencia social de un mundo que se vuelve excesivamente pragmático e inmediatista y que vive un acelerado proceso de secularización.

La cercanía del hablante con Jesucristo es un tema penetrante en el poema "Yoísmo" donde el yo poético señala: "yo soy la encarnación de los divinos/ Cristo fue la encarnación de los humanos!". La teología cristiana señala que la Encarnación es el hecho de que el Hijo de Dios haya asumido una naturaleza humana para asegurar nuestra salvación. San Pablo representa este hecho así: "[Cristo] se despojó de sí mismo tomando condición de siervo, haciéndose semejante a los hombres y apareciendo en su porte como hombre; y se humilló a sí mismo, obedeciendo hasta la muerte y muerte de cruz." (Flp 2, 5-8)

Así como la naturaleza divina de Jesús pudo hacerse carne para sufrir y salvar a la humanidad, el hablante, por medio de la letra, se identifica con Jesús como si él mismo fuese otro elegido que también procede de una naturaleza especial, casi divina. Es por esto que, para el hablante, la pasión del poeta es plenamente identificable con la Pasión de Cristo: 
Y ruedo por la tierra con una fuerza extraña que me empuja al camino y ensangrienta mis huellas pone flores y espinas y dolor de montaña (15) en mi amor miserable por pastorear estrellas. (Autorretrato)

En estos versos, el "camino", las "huellas ensangrentadas", las "flores", "espinas" y el "dolor de la montaña", nos recuerdan el atormentado camino de Jesucristo al Monte Calvario, camino que también recorre el poeta, metafóricamente, mientras transita por la vida revelando realidades poco gratas de oír o sin valor para una sociedad capitalista que desplaza progresivamente a Dios. Por otra parte, el pastoreo también puede ser considerado como un ejercicio común a ambos pues la imagen de la conducción del ganado simbolizaría la necesidad de que un ser superior guíe una sociedad que se vuelve ingobernable. Tanto Cristo como el hablante deben peregrinar junto a los hombres y orientarlos en el desenvolvimiento de su experiencia vital. Así, este último estaría imitando la tarea de salvación llevada a cabo por Cristo.

Otra actitud consistente con este deseo de imitar a Cristo es el desprecio de las cosas materiales y la baja estimación de sí mismo ante Dios. Sin embargo, hay un punto en el que el hablante se distancia de Jesús. Esto ocurre porque no demuestra aceptación incondicional a la voluntad divina como hizo Cristo cuando aceptó su martirio. La actitud del hablante es la de un hombre abatido que se niega a encontrar sentido en el camino que le tocó recorrer:

La voluntad divina que echó a rodar los astros (1) -la que empuja a la vida, la que a la muerte encierracon mil signos de estrellas predestinó los rastros de mi ruta mortal y fatal por la tierra.

\section{(Autorretrato)}

De lo mencionado anteriormente se desprende que el hablante no está dispuesto a renunciar a sí mismo ni a sus deseos. Su sufrimiento no está consagrado a Dios, ni tampoco logra vislumbrar un sentido allende a ese dolor. En este punto, el hablante se distancia del verdadero significado que involucra el hecho de "llevar la cruz". Esto es, la espera de la redención tras los martirios que nos parecen incomprensibles e injustificados. ¿Cómo entender, entonces, semejante tormento y tristeza por parte del hablante si no es para encontrar un sentido más profundo? Es demasiado frívolo suponer que se trata de un artificio del poeta para nutrir su inspiración pero, hasta acá es difícil despejar el dilema. Dejamos planteada la inquietud. 


\subsection{La vida como tránsito hacia la muerte}

En la poesía de Gómez Rojas, la vida es presentada habitualmente como un tránsito con orientación clara; el encuentro de la paz después de la muerte. Sin embargo, este tránsito no contempla un destino final previamente determinado, como podría ser la llegada al Paraíso. El hablante reconoce que no puede saber si encontrará paz después de su muerte pero, de todas maneras, añora que ésta llegue pues cree que lo liberará de sus ataduras al mundo y que será un descanso para sus tribulaciones. Sin embargo, esto no significa necesariamente la dicha eterna:

Amo tanto la muerte, que la vida para mí es un instante de los tiempos, por eso amo la sombra del camino por donde van los muertos.

(Voy por el mundo...) (10)

En el poema Voy por el Mundo... el tránsito del sujeto textual por la vida es errático y demuestra contradicciones pues, a pesar de que señala apreciar la vida, aprecia de igual modo la muerte. Lo único claro es que está consciente de que la vida es una experiencia provisoria e incomparable con la rotunda y eterna muerte: "Por eso estoy soñando con la muerte, / -futuro de silencio-" (Voy por el Mundo...)

La fugacidad de la vida y la necesidad de despegarse de lo que lo ata al mundo material, hacen que el hablante descubra su situación de precariedad. Éste se niega a sí mismo: "Voy por el mundo y soy apenas sombra/ de lo divino que decir no puedo..." (Voy por el Mundo...) En el poema Autorretrato, el tránsito del sujeto textual por la vida suele perder rumbo y éste comienza a deambular desorientado cuando la muerte ya ni siquiera puede ofrecer una esperanza al fin del sufrimiento:

Y camino...camino. Por la noche y el día sobre mi sombra el tiempo su ácido negro vierte yo se qué, fatalmente, por la tierra sombría soy un muerto que vive esperando la muerte. (20)

La actitud agónica es muestra de un cansancio intenso, propio de un condenado que deambula a la espera del fin. El hablante se va desarticulando para atender sólo a su espiritualidad, desea que su propia materia se esfume para hacerse liviano, y ascender pues no le debe nada a la materia: 
Yo soy como un fantasma misterioso (15)

que por la sombra de un abismo erra;

yo soy como un sonido doloroso

que vibrara muy lejos de la tierra.

(Yoísmo)

Y puede llegar incluso a difuminar su propia imagen hasta convertirse en una sombra, metáfora espacial del sufrimiento: "Voy por el mundo y soy apenas sombra/ de lo divino que decir no puedo." (Voy por el mundo...) Ante esta sensación de invalidez dada por el rotundo "no puedo" y la imposibilidad de conocer la divinidad más profundamente, tanto el hombre como el hablante comienzan a alejarse del mundo, textual e históricamente. Ambos desean desprenderse de las cargas onerosas del cuerpo y, ante la incapacidad de asir lo divino, sustituyen su deseo de elevarse por una experiencia más terrenal de la divinidad.

Como se observa hasta aquí, la visión del hablante respecto de la muerte no significa el cese del ser sino, más precisamente, la posibilidad de desprenderse de un cuerpo que agota al hombre en todo el sentido de la palabra. Para el hablante, "estar muerto" es un cambio ligeramente positivo respecto de estar vivo y sufriendo. Su actitud pesimista ante la vida revela una aguda falta de esperanza histórica y escatológica que, según creemos, trasluce las propias inquietudes del poeta.

\subsection{Tensión entre lo mundano y lo sagrado}

La oposición entre estos ámbitos se presenta intensamente en la poesía de Gómez Rojas. Quizás esto ocurre porque el poeta se siente en una encrucijada. Por un lado, desea fervientemente escapar de un mundo corrupto que lo abruma pero, por otro, su cuerpo anclado a este mundo, le impide huir. La única forma en que podrá hacerlo será por medio de la poesía que, como una instancia de refugio, le ofrece cierta quietud para su interioridad contrariada. Al ser Gómez Rojas un hombre de fe es indudable que conoce acerca de la compasión que el Dios cristiano deposita sobre sus criaturas. Él tratará de acogerse a este favor mediante la poesía pero ésta no logra abstraerlo del todo pues su vida no puede darse al margen del mundo material. Es así como el hablante expresa la contrariedad del poeta.

En todo caso, debemos precisar que, en estos versos, la materia y la divinidad se distinguen enfrentadas, mas no divorciadas. El hablante se sitúa ante la materialidad fría y agobiante de las cosas como si lo palpable degradara la dimensión trascendente del hombre. La suya no 
es una experiencia humana celebratoria de las cosas físicas como lo es en el caso del hablante mistraliano, sino que, en Gómez Rojas, se trata de un lamento por la proliferación ridícula de la materia en detrimento del crecimiento espiritual, condición que pareciera despojar al hombre de su posibilidad de experimentar lo divino, lo empequeñece, aísla y, finalmente, lo aliena.

El lamento a causa del repliegue de lo trascendente en el mundo y la secularización de la experiencia de lo divino son rasgos que Gómez Rojas simboliza muy logradamente en su poesía. Por ejemplo, el contraste entre la aridez de la materia profana y los atributos simbólicos de lo sagrado provoca una ansiedad profunda en el hablante quien, al encontrarse incapacitado de acceder al conocimiento de lo divino, en la medida que él mismo es materia, realiza un vuelco y ya no intentará ser él quien se encumbre hacia las alturas celestiales sino que acercará hacía sí las propiedades de lo sagrado al identificarlas con el espacio sideral, el lugar físico más elevado en la Tierra y, por tanto, un poco más a su alcance. Este sutil giro del significante "cielo" no puede calificarse como una profanación pero, ciertamente, constituye una muestra de la secularización de la experiencia de lo divino en la modernidad.

La identificación de la divinidad con la bóveda celeste es un rasgo reiterado en el poema "Autorretrato". En éste, los astros actúan como agentes impulsores del curso de la vida como si el destino hubiese sido sellado por éstos, al margen de la voluntad del hombre:

El horóscopo azul de invisibles cadenas -bajo cielos inmensos, eternos y profundosvertió en mi forma humana la sangre por las venas y sometió mis carnes al ritmo de los mundos.

\section{(Autorretrato)}

Sin embargo, aún cuando la suerte dependa de los astros, el hablante reconoce que Dios es la fuerza superior que los creó; por lo tanto, nada se escapa a Su voluntad. Recordemos estos versos:

La voluntad divina que echó a rodar los astros

-la que empuja a la vida, la que a la muerte encierracon mil signos de estrellas predestinó los rastros de mi ruta mortal y fatal por la tierra.

(Autorretrato)

La intención de configurar la identidad se evidencia en la actitud autorreflexiva de este yo poético que, para retratarse, debe comenzar 
señalando que no es por sí sino por Dios. El hablante se enfrenta a sí mismo aceptando que tanto la finitud de su cuerpo como su posibilidad de trascender le fueron dadas por el Creador. Se reconoce como una criatura de Dios con satisfacción aun cuando la existencia misma lo conflictúe.

Otra manera en que se muestra la secularización de la experiencia de lo divino es a través de la inscripción del cuerpo humano como un agente degradante que provoca el alejamiento de lo sagrado. Esta idea alcanza un nivel humorístico en el poema "Profanación" cuyo tema condena la mirada lasciva de un monaguillo hacia una dama en el momento de la Comunión:

El órgano sonoro

tocó una antífona desde el coro (10)

y empezó el sacerdote a dar la comunión;

y cuando recibías la blanca hostia de harina

un monaguillo imbécil en tu boca divina,

posó larga mirada llena de tentación.

\section{(Profanación)}

En este poema el significante "órgano" supera su acepción de instrumento musical y sugiere -freudianamente-cómo la materia se "alza" en el mismísimo aposento de lo sagrado. La estrofa citada muestra la convivencia simultánea del respeto por lo divino y su profanidad (que no profanación).

En los dos últimos versos de esta estrofa, observamos que el hablante eleva a la dama a la condición de divinidad. Esto podría considerarse como una sacralización del léxico profano puesto que, al decir de Gutiérrez Girardot, también en la modernidad "se ha sacralizado el eros."(58) Quizás lo que ese vínculo sugiere es que, para el hablante, la mujer es igual de inalcanzable que la divinidad.

La imagen réproba que presenta esta estrofa no hace más que confirmar la instalación de una nueva forma de relacionarse con Dios. Constituye un contacto personal que abandona la concepción inspectoril y castigadora de Dios, y lo humaniza para acercarlo más.

\section{Conclusiones}

Como se ha visto hasta aquí, la religiosidad del hablante concuerda con las inquietudes personales del poeta sobre Dios, Jesucristo y el cristianismo. Gómez Rojas se distancia de los ritos prescritos por alguna 
iglesia, y privilegia una relación más directa y personalizada con Dios. Este cambio proviene de una reflexión profunda en torno al mensaje de amor de Jesucristo que, a juicio del poeta, no se está llevando a cabo pues la sociedad moderna con su racionalidad pragmática no se detiene a observar al prójimo con compasión; a veces, ni siquiera lo ve. Así, Gómez Rojas se repliega hacia sí mismo y reflexiona sobre lo lamentable que es una existencia intrascendente. Una vez que el poeta superó la etapa crítica de su cuestionamiento, se despertó en él el deseo de rearticular su relación con Dios.

Esta nueva forma se abrió camino a través de su poesía de inspiración cristiana, donde el hablante recorre dos caminos principalmente. Por un lado, medita sobre la materia como un elemento degradante que oprime al hombre y afecta su capacidad de trascender. La única evasión posible ante la aplastante crueldad de ésta es refugiarse en el lugar más alto dentro del mundo: el espacio sideral. Aquí los astros se vuelven depositarios de valores trascendentes, denotando una marcada impronta panteísta en la poesía. En segundo lugar, el hablante se centra en la figura esencial de Cristo y exalta su relación directa con los hombres. Asimismo, el hablante mantiene una actitud de respeto hacia los signos sensibles de la gracia de Dios: los sacramentos. No obstante, debemos recordar que la dimensión ritualista de la religión no es para el hablante la única forma en que se hace presente la gracia divina. Lo más importante es la dimensión consecuencial, es decir, las acciones concretas que patentizan el mensaje religioso en la experiencia cotidiana.

El distanciamiento que experimentan los hombres respecto del mensaje de Dios fue una triste revelación para Gómez Rojas, quien trató el tema recurrentemente a través de su voz poética. Este hablante, a su vez, advirtió que el quehacer del mundo moderno no está consagrado a Dios en su fin último ya que en la modernidad todo se proyecta, consuma y agota en su materialidad. Es por ello que, en este contexto, la relación con Dios adquiere un nuevo semblante, caracterizado por una devoción cada vez más personalizada.

Por desencantadora que parezca la revelación de que los hombres desean desarrollar su vida al margen de Dios, consideramos que la forma en que el hablante ha tratado el tema es constructiva pues acepta la omnisciencia de Dios y jamás comete una "profanación". Aún cuando la separación entre éstos y Aquél parece progresiva e irreversible, el hablante continúa creyendo en Dios y buscando mantener el contacto con la divinidad desde su realidad marginal y profana, sin dejar de aspirar a lo divino. Esta forma de aproximación bien puede considerarse honesta 
porque demuestra el genuino interés de un individuo por traspasar la barrera de lo inmanente y trascender, luego de reconocer su lugar de enunciación: la precariedad del hombre respecto de Dios.

Por último, observamos que, para el hablante de Gómez Rojas, no se trata de que el mundo trascendente haya sido degradado ni mucho menos sustituido por uno inmanente, sino de que el sujeto moderno es colocado ante sí mismo y debe lidiar con los múltiples aspectos de su realidad.

\section{Bibliografía}

Arteche, Miguel y Rodrigo Cánovas. Antología de la poesía religiosa chilena. Santiago: Ediciones Universidad Católica de Chile. 2000 .

Berman, Marshall. Todo lo sólido se desvanece en el aire. La experiencia de la modernidad. México: Siglo XXI editores. 2008.

Gissi, Jorge. Psicología e identidad latinoamericana. Sociopsicoanálisis de cinco premios nobel de literatura. Santiago: Ediciones Universidad Católica de Chile. 2002.

Livacic, Ernesto et al. La inquietud religiosa en la obra de cuatro poetas chilenos contemporáneos. Miguel Arteche, Carlos Bolton, Fidel Sepúlveda y Raúl Zurita. Santiago: Instituto de Letras, Pontificia Universidad Católica de Chile. s/f.

Oviedo Torró, Lluís. La secularización como problema. Valencia: Facultad de Teología San Vicente Ferrer. 1990.

Roa, Armando. Modernidad y postmodernidad. Coincidencias y diferencias fundamentales. Santiago: Andrés Bello. 1995.

\section{Bibliografía específica}

Droguett, Iván. (s/d) "José Domingo Gómez Rojas, un poeta crepuscular" p. 136.

Gómez Rojas, José Domingo. Elegías. Santiago: Nascimento. 1935.

Moraga, Fabio. y Vega, Carlos. José Domingo Gómez Rojas. Vida y obra. Punta Arenas: Editorial Ateli. 1997.

Rojas, Manuel. "Recuerdos de José Domingo Gómez Rojas". Babel. Revista de arte y crítica, (1945, julio-agosto): 28, 26- 33.

Sabella, A. "Popularización de Gómez Rojas". La Nación. (1939, 8 de octubre). 